\title{
EFEITO DA ADUBAÇÃO ALTERNATIVA DO MARACUJAZEIRO- AMARELO NAS CARACTERÍSTICAS QUÍMICAS E FÍSICAS DO SOLO ${ }^{(1)}$
}

\author{
André Assis Pires ${ }^{(2)}$, Pedro Henrique Monnerat ${ }^{(3)}$, Cláudio Roberto \\ Marciano $^{(4)}$, Leandro Glaydson da Rocha Pinho ${ }^{(5)}$, Poliana Daré \\ Zampirolli $^{(6)}$, Raul Castro Carriello Rosa ${ }^{(7)}$ \& Rodrigo Almeida Muniz ${ }^{(8)}$
}

\begin{abstract}
RESUMO
Adubações minerais e orgânicas promovem alterações nas condições físicas e químicas do solo, com conseqüente efeito na produtividade das culturas. Um experimento foi realizado no Município de Campos dos Goytacazes, RJ, de fevereiro de 2005 a julho de 2006, para comparar diferentes adubos orgânicos com a adubação mineral do maracujazeiro-amarelo quanto aos efeitos sobre as características químicas e físicas do solo adubado. O delineamento experimental foi em blocos casualizados, com quatro repetições e seis tratamentos, correspondentes às seguintes adubações por planta: $(\mathrm{AM})$ adubação mineral $=100 \mathrm{~g}$ da fórmula NPK 20-5-20 + cobertura morta (CM); EB = $5 \mathrm{~L}$ de esterco bovino + CM; FOC = 500 g de farinha de ossos e carne $+\mathrm{CM} ; \mathrm{RM}=5 \mathrm{~L}$ de raspa de mandioca $+\mathrm{CM}$; $\mathrm{TF} \mathrm{C} / \mathrm{CM}=5 \mathrm{~L}$ de torta de filtro $+\mathrm{CM}$; TF $\mathrm{S} / \mathrm{CM}=5 \mathrm{~L}$ de torta de filtro - sem CM. A adubação mineral foi feita a cada 30 dias e as adubações orgânicas a cada 60 dias. Foram avaliados os atributos químicos: $\mathrm{pH}$, condutividade elétrica, teores de $\mathrm{P}, \mathrm{K}, \mathrm{Ca}, \mathrm{Mg}$, $\mathrm{Na}, \mathrm{Al}, \mathrm{H}+\mathrm{Al}$, e matéria orgânica; e os físicos: granulometria, densidade do solo e das partículas, porosidade total, macro e microporosidade, capacidade de campo, ponto de murcha e água disponível em três diferentes profundidades $(0-5,5-10$, 10-15 cm). Os adubos orgânicos aplicados no maracujazeiro promoveram mudanças
\end{abstract}

\footnotetext{
(1) Parte da Tese de Doutorado do primeiro autor. Recebimento para publicação em outubro de 2007 e aprovado em junho de 2008.

(2) Engenheiro-Agrônomo, M.Sc., Doutorando em Produção Vegetal, Universidade Estadual do Norte Fluminense Darcy Ribeiro - UENF/CCTA/LFIT. Av. Alberto Lamego 2000, Horto, CEP 28015-620 Campos dos Goytacazes (RJ). Bolsista FAPERJ. Emails: assis@uenf.br; andre@eafcol.gov.br

(3) Engenheiro-Agrônomo, Ph D, UENF/CCTA/LFIT. E-mail: monnerat@uenf.br

(4) Engenheiro-Agrônomo, D. Sc., UENF/CCTA/LSOL. E-mail: marciano@uenf.br

${ }^{(5)}$ Licenciado em Ciências Agrícolas, M.Sc., Doutorando em Produção Vegetal, UENF/CCTA/LFIT. Bolsista FAPERJ. E-mail: pinho@uenf.br

(6) Engenheira-Agrônoma, M.Sc., Doutoranda em Produção Vegetal, UENF/CCTA/LFIT. E-mail: poliana@uenf.br

(7) Engenheiro-Agrônomo, D.Sc., UENF/CCTA/LFIT. E-mail: carrielo@uenf.br

(8) Aluno de Agronomia, UENF/CCTA/LFIT. E-mail: uenf.rodrigo@gmail.com
} 
significativas nas características químicas do solo, em comparação com a adubação mineral tradicional, em que houve aumento do $\mathrm{pH}$ e do $\mathrm{H}+\mathrm{Al}$ em todas as profundidades, e redução dos teores de Al nas camadas mais profundas. Houve, ainda, aumento nos teores de nutrientes no solo e, por conseqüência, na soma de bases, principalmente na camada superior, sendo a torta de filtro o composto orgânico mais eficiente em promover tais melhorias, inclusive aumentando a CTC do solo. Apenas a torta de filtro promoveu alterações nas características físicas do solo, reduzindo as quantidades de areia grossa e aumentando as quantidades de silte, argila e matéria orgânica. As demais características físicas do solo não foram influenciadas pela adição de adubos orgânicos no maracujazeiro, em comparação com a adubação mineral tradicional.

Termos de indexação: Adubação orgânica, adubação mineral, fertilidade do solo, Passiflora edulis.

\section{SUMMARY: ALTERNATIVE MANURING OF THE YELLOW PASSION FRUIT PLANT: EFFECTS ON CHEMICAL AND PHYSICAL CHARACTERISTICS OF THE SOIL}

The supply of mineral and organic manuring promotes alterations in the physical and chemical conditions of the soil, with consequent effects on crop productivity. An experiment was accomplished in the county of Campos dos Goytacazes, RJ, from February 2004 to July 2006, to compare different organic fertilizers with the traditional chemical manuring of the yellow passion fruit plant regarding their effects on chemical and physical characteristics of the fertilized soil. The experiment had a randomized complete block design with four replicates, with six treatments of fertilizer levels per plant as follows: (AQ) Chemical manuring $=100 \mathrm{~g}$ of the formula $20-5-20\left(\mathrm{~N}-\mathrm{P}_{2} \mathrm{O}_{5}-\mathrm{K}_{2} \mathrm{O}\right)+$ mulching $(\mathrm{CM}) ; \mathrm{EB}=5 \mathrm{~L}$ of bovine manure $+C M ; F O C=500 \mathrm{~g}$ of bone and meat flour $+C M ; R M=5 \mathrm{~L}$ of cassava abrades $+C M ; T F+C M=5 L$ of sugar cane plant filter pie $+C M ; T F=5 L$ of sugar cane filter pie without CM. Chemical manuring was done every 30 days, while organic manuring every 60 days. The soil chemical characteristics ( $p H$, electric conductivity, levels of $P, K$, $\mathrm{Ca}, \mathrm{Mg}, \mathrm{Na} \mathrm{Al}, \mathrm{H}+\mathrm{Al}$, and organic matter) and physical characteristics (granulometry, density of the soil and of the particles, total porosity, macro and microporosity, field capacity, wilting point and water availability) were determined in $0-5,5-10,10-15 \mathrm{~cm}$ soil layers. The organic fertilizers applied to passion fruit plant modified significantly the soil chemical characteristics, in comparison to the traditional chemical manuring, increasing $\mathrm{pH}$ and $H+A l$ in all soil depths, and reducing $\mathrm{Al}$ availability in the deepest layers. There was also an increase in the availability of nutrients in the soil and so in the sum of bases, mainly in the surface layer, the filter pie being the most efficient organic manure in promoting such improvements, besides increasing soil CTC. Only the filter pie modified the soil physical characteristics, reducing the amounts of coarse sand and increasing the amounts of silt, clay and organic matter. The other physical characteristics of the soil were not influenced by the addition of organic fertilizers to the passion fruit plant, in comparison with the traditional chemical fertilizers.

Index terms: Organic manuring, chemical manuring, soil fertility, Passiflora edulis.

\section{INTRODUÇÃO}

O maracujazeiro é uma cultura muito difundida em todas as regiões do Brasil, tanto pelas condições edafoclimáticas altamente favoráveis quanto pela aceitação de seu fruto para o consumo in natura e para a indústria de polpa de frutas. Nos últimos anos, o cultivo do maracujá-amarelo vem sendo realizado principalmente por pequenos agricultores, na maioria dos casos com mão-de-obra familiar e poucos recursos financeiros para investir na cultura, de modo que alternativas para reduzir o custo de produção são essenciais para torná-la uma cultura viável. Em termos nutricionais, uma alternativa é a substituição do adubo mineral, de preços elevados, por produtos de origem vegetal e animal disponíveis no campo, que, além de ter preços mais acessíveis, influenciam positivamente com a matéria orgânica as propriedades químicas, físicas e biológicas do solo. 
Essa influência é considerada fundamental para a manutenção da capacidade produtiva em qualquer ecossistema terrestre. Do ponto de vista físico, melhora a estrutura do solo, reduz a plasticidade e a coesão, aumenta a capacidade de retenção de água e a aeração, permitindo maior penetração e distribuição das raízes. Atua também diretamente sobre a fertilidade do solo, sendo importante fonte de macro e micronutrientes, como também indiretamente, elevando o $\mathrm{pH}$ e aumentando a capacidade de retenção dos nutrientes.

No Norte Fluminense, há considerável quantidade de resíduos orgânicos, dentre os quais destacam-se o esterco bovino, os resíduos das indústrias sucroalcooleiras, das farinheiras de mandioca e das indústrias de processamento de carcaças bovinas. Por isso, a adubação orgânica, ou mesmo a associação desta com a adubação mineral, constitui alternativas para os produtores desta região.

Pouco se conhece sobre o efeito desses materiais orgânicos sobre as características químicas e físicas de solos cultivados com maracujazeiro. Gomes et al. (2005), comparando o uso de esterco bovino com a adubação mineral (4-14-8) na cultura do milho, verificaram que o adubo mineral promoveu a redução do tamanho médio dos agregados, a redução dos teores de $\mathrm{Ca}, \mathrm{Mg}$ e K do solo, aumento do teor de $\mathrm{P}$ do solo, e verificaram também aumento dos teores de carbono orgânico, $\mathrm{Ca}, \mathrm{Mg}, \mathrm{K}$ e P do solo nos tratamentos com compostos orgânicos. Tanto o adubo mineral quanto o composto orgânico não interferiram nas densidades do solo e de partículas e na porosidade total do solo.

Holanda et al. (1984) verificaram aumento linear dos valores de $\mathrm{pH}$, e teores de $\mathrm{Ca}, \mathrm{Mg}, \mathrm{K}$ e $\mathrm{P}$, além de decréscimo nos teores de $\mathrm{Al}$ trocável, com as doses de esterco. Scherer et al. (2007), avaliando as propriedades químicas de um Latossolo Vermelho cultivado com milho, verificaram que a aplicação de esterco de suínos em superfície (sem incorporação) teve efeito positivo apenas nos teores de $\mathrm{P}$ das camadas superficiais (até $10 \mathrm{~cm}$ de profundidade), não sendo constatados efeitos sobre a acidez do solo, teores de cátions básicos, a CTC e teor de matéria orgânica do solo.

Diversos trabalhos têm sido realizados com outros tipos de materiais orgânicos em diversas culturas, sendo encontrados importantes resultados nas melhorias das características físicas e químicas dos solos estudados. Dentre esses, Melo \& Marques (2000) e Marciano et al. (2001) estudaram os efeitos do lodo de esgoto sobre as propriedades físicas do solo, enquanto Silva et al. (2002), Cavallaro et al. (1993) e Oliveira et al. (2002b) avaliaram os efeitos sobre as propriedades químicas. O uso de composto de lixo também tem sido bastante estudado, sendo relatados efeitos sobre o solo em seus atributos físicos (Marciano et al., 2001), químicos (Oliveira et al., 2002a) ou ambos (Abreu Junior et al., 2000).

Este trabalho teve por objetivo comparar o efeito de diferentes fontes de adubos orgânicos com os da adubação mineral tradicional na cultura do maracujazeiro-amarelo, nas características químicas e físicas em diferentes profundidades do solo.

\section{MATERIAL E MÉTODOS}

O experimento foi conduzido de fevereiro de 2005 a julho de 2006, em uma lavoura comercial de maracujáamarelo (Passiflora edulis Sims f. flavicarpa Deg) sem irrigação, instalada em outubro de 2004 , nas coordenadas $21^{\circ} 41^{\prime} 49,1^{\prime}$ " S e $41^{\circ} 15^{\prime} 05$ ” W, em Campos dos Goytacazes, RJ. O solo da área, classificado como Neossolo Flúvico Psamítico, foi previamente amostrado na profundidade de $0-20 \mathrm{~cm}$. Os resultados da análise química são apresentados no quadro 1. A análise granulométrica revelou teores médios de $60 \mathrm{~g} \mathrm{~kg}^{-1}$ de argila, $20 \mathrm{~g} \mathrm{~kg}^{-1}$ de silte e $920 \mathrm{~g} \mathrm{~kg}^{-1}$ de areia, sendo definido quanto à classe textural como "areia".

O plantio das mudas de maracujá se deu em 10 de outubro de 2004, utilizando $5 \mathrm{~L}$ de torta de filtro no fundo da cova em todas as plantas. Antes da instalação do experimento, foram feitas duas adubações de cobertura em todas as plantas, uma em dezembro de 2004 e outra em janeiro de 2005, aplicando-se $100 \mathrm{~g}$ de 20-5-20 por planta. As plantas foram conduzidas no sistema de espaldeira vertical em haste única até o fio de arame, e, em seguida, em dois ramos horizontais em sentidos opostos, ao longo do fio. As unidades

Quadro 1. Características químicas da camada arável do solo (0-20 cm) antes da aplicação dos tratamentos

\begin{tabular}{|c|c|c|c|c|c|c|c|c|c|c|c|c|c|c|c|c|}
\hline \multirow[b]{2}{*}{$\mathrm{pH} \mathrm{H}_{2} \mathrm{O}$} & \multirow[b]{2}{*}{$\mathrm{Al}^{3+}$} & \multirow[b]{2}{*}{$\mathrm{H}+\mathrm{Al}$} & \multirow[b]{2}{*}{$\mathrm{Ca}^{2+}$} & \multirow[b]{2}{*}{$\mathrm{Mg}^{2+}$} & \multirow[b]{2}{*}{$\mathbf{K}^{+}$} & \multirow[b]{2}{*}{$\mathbf{P}$} & \multirow[b]{2}{*}{$\mathrm{Fe}$} & \multirow[b]{2}{*}{$\mathrm{Cu}$} & \multirow[b]{2}{*}{$\mathrm{Zn}$} & \multirow[b]{2}{*}{ Mn } & \multirow[b]{2}{*}{ B } & \multirow[b]{2}{*}{$\mathbf{S}$} & \multirow[b]{2}{*}{$\mathrm{CO}$} & \multicolumn{2}{|c|}{ CTC } & \multirow[b]{2}{*}{ V } \\
\hline & & & & & & & & & & & & & & Efetiva & pH 7 & \\
\hline$(1: 2,5)$ & 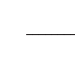 & $\mathrm{mm}$ & $l_{c}{d m^{-3}}^{-3}$ & 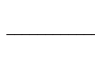 & - & 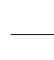 & 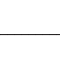 & - & $\mathrm{dm}^{-3}$ & & & & $\mathrm{~g} \mathrm{~kg}^{-1}$ & $-\mathrm{mmo}$ & $m^{-3}-$ & $\%$ \\
\hline 5,3 & 0 & 36 & 18 & 7 & 1 & 27 & 35 & 0,2 & 0,9 & 3,2 & 0,2 & 7,5 & 10,4 & 26 & 62 & 42 \\
\hline
\end{tabular}

Extratores: $\mathrm{Ca}, \mathrm{Mg}, \mathrm{Al}\left(\mathrm{KCl} 1 \mathrm{~mol} \mathrm{~L}^{-1}\right) ; \mathrm{H}+\mathrm{Al}: \mathrm{Ca}\left(\mathrm{C}_{2} \mathrm{H}_{3} \mathrm{O}_{2}\right)_{2}$ 0,5 mol L ${ }^{-1} ; \mathrm{P}, \mathrm{K}, \mathrm{Fe}, \mathrm{Cu}, \mathrm{Zn}, \mathrm{Mn}\left(\mathrm{HCl} \mathrm{0,05} \mathrm{mol} \mathrm{L^{-1 } + \mathrm { H } _ { 2 } \mathrm { SO } _ { 4 }}\right.$ $\left.0,0125 \mathrm{~mol} \mathrm{~L}^{-1}\right)$; $\mathrm{S}:\left(\left(\mathrm{Ca}\left(\mathrm{H}_{2} \mathrm{PO}_{4}\right)_{2}, 500 \mathrm{mg}\right.\right.$ de $\left.\mathrm{P}, \mathrm{HOAc} 2 \mathrm{~mol} \mathrm{~L}^{-1}\right)$; B: água quente. 
experimentais foram constituídas de três fileiras com sete plantas cada, totalizando 21 plantas por parcela, em espaçamento de $3 \times 2 \mathrm{~m}$.

As adubações de cobertura que compuseram os tratamentos iniciaram-se em março de 2005, finalizando em abril de 2006 para o mineral e, em junho de 2006, para os tratamentos orgânicos, sendo as adubações minerais realizadas com intervalos de aplicação de 30 dias e as orgânicas com intervalos de 60 dias, totalizando treze adubações minerais e oito orgânicas. As adubações minerais e orgânicas foram realizadas de acordo com o que é comumente realizado pelos produtores de maracujá da região norte fluminense, ou seja, $100 \mathrm{~g}$ de adubo mineral e $5 \mathrm{~L}$ do material orgânico por cova. Os adubos foram aplicados a uma distância média de $10 \mathrm{~cm}$ do caule, numa faixa de $20 \mathrm{~cm}$ de largura em torno da planta.

Os tratamentos consistiram na combinação de doses de adubos minerais e orgânicos. Os tratamentos foram: $1 . \mathrm{AM}=100 \mathrm{~g}$ adubo mineral (20-5-20) (formulado com uréia) + cobertura morta (CM); 2. EB $=5 \mathrm{~L}$ esterco bovino $+\mathrm{CM} ; 3$. FOC $=500 \mathrm{~g}$ farinha de osso e carne $+\mathrm{CM} ; 4 . \mathrm{RM}=5 \mathrm{~L}$ raspa de mandioca $+\mathrm{CM} ; 5$. TFCM $=5$ L torta de filtro + CM; 6. TFSCM $=5 \mathrm{~L}$ torta de filtro sem CM. O delineamento experimental utilizado foi o de blocos casualizados com quatro repetições. A composição química dos compostos que constituíram os tratamentos encontra-se no quadro 2.

A cobertura morta foi composta por restos vegetais das plantas daninhas roçadas nas entrelinhas do maracujazeiro, sendo as mais comuns o capim-colonião (Panicum maximum), trapoeraba (Commelina bengalensis L.) e capim-mimoso (Eragrostis pilosa L.). A cobertura foi posta juntamente com a primeira adubação, e reposta a cada dois meses a fim de restituir o que se degradou ou se perdeu das aplicações anteriores.

Em julho de 2006, após o encerramento das coletas de frutos e folhas do maracujazeiro, iniciou-se a coleta de solos para a realização das avaliações químicas e físicas do solo. Para a realização das análises químicas, foram coletadas amostras deformadas de solo utilizando um trado de sonda em três diferentes profundidades $(0-5,5-10,10-20 \mathrm{~cm})$ das três plantas centrais da área útil de cada parcela, totalizando 72 amostras. Para a realização das análises físicas, foram coletadas amostras indeformadas, a $30 \mathrm{~cm}$ de distância do caule da terceira planta da área útil de cada parcela, em anéis volumétricos com dimensões aproximadas de $50 \mathrm{~mm}$ de altura e $50 \mathrm{~mm}$ de diâmetro interno, em três diferentes profundidades $(0-5,5-10$, $10-15 \mathrm{~cm})$, sendo duas amostras por profundidade, ou seja, seis amostras por parcela, totalizando 144 amostras.

Todas as amostras foram embrulhadas em papel alumínio, acondicionadas em sacolas plásticas e levadas ao laboratório de Nutrição Mineral de Plantas da Universidade Estadual do Norte Fluminense Darcy Ribeiro. Foram avaliados o $\mathrm{pH}$, a condutividade elétrica (CE), os teores disponíveis de $\mathrm{P}, \mathrm{K}^{+}, \mathrm{Ca}^{2+}, \mathrm{Mg}^{2+}$, $\mathrm{Na}^{+}, \mathrm{Al}^{3+}, \mathrm{H}+\mathrm{Al}$, e o teor de $\mathrm{MO}$, além da CTC em pH 7 e da soma de bases (SB), segundo as marchas analíticas apresentadas em Embrapa (1997). O carbono orgânico foi determinado com dicromato de potássio por colorimetria, pelo método descrito por Anderson \& Ingran (1996). As características físicas avaliadas foram os teores de argila, areia fina e grossa, silte, densidade do solo e de partículas, porosidade total, macro e microporosidade, água disponível, capacidade de campo e ponto de murcha, segundo os métodos descritos em Embrapa (1997).

Para a análise de variância admitiu-se o esquema de parcelas subdivididas, sendo o fator adubação considerado como parcela e o fator profundidade como subparcela. Dessa forma, havendo efeito da interação profundidade x adubação, as médias dos tratamentos orgânicos foram comparadas, para cada profundidade, com a média do tratamento mineral (testemunha) pelo teste de Dunnett a $5 \%$, enquanto as médias das profundidades foram comparadas entre si, para cada adubação, pelo teste de Tukey, a 5 \%. Por outro lado, havendo apenas os efeitos simples desses fatores, as profundidades foram comparadas entre si na média de todas as adubações, enquanto as adubações foram comparadas na média das três profundidades (as orgânicas vs a mineral), respectivamente pelos testes de Tukey e Dunnett (ambos a 5 \% de significância).

Quadro 2. Teores de nutrientes minerais médios encontrados na matéria seca dos materiais orgânicos utilizados no experimento de maracujá

\begin{tabular}{|c|c|c|c|c|c|c|c|c|c|c|c|c|c|c|}
\hline Material orgânico & $\mathbf{N}$ & $\mathbf{P}$ & $\mathbf{K}$ & $\mathbf{C a}$ & Mg & $\mathbf{S}$ & $\mathrm{Cl}$ & $\mathbf{N a}$ & Mo & $\mathbf{B}$ & $\mathrm{Zn}$ & $\mathrm{Cu}$ & $\mathrm{Fe}$ & Mn \\
\hline & & & & \multicolumn{5}{|c|}{$-\mathrm{g} \mathrm{kg}^{-1}$} & \multicolumn{6}{|c|}{$-\mathrm{mg} \mathrm{kg}^{-1}$} \\
\hline Torta de filtro & 7,9 & 15 & 1,2 & 99 & 15 & 7,2 & 0,9 & 0,3 & 38 & 8,8 & 393 & 29 & 17.042 & 755 \\
\hline Esterco bovino & 13 & 4,9 & 6,0 & 8,5 & 10 & 4,9 & 1,3 & 0,3 & 18 & 12 & 259 & 15 & 13.424 & 336 \\
\hline Raspa de mandioca & 3,2 & 1,2 & 2,2 & 11 & 2,3 & 7,5 & 0,9 & 0,7 & 4,5 & 15 & 13.287 & 23 & 7.587 & 90 \\
\hline Farinha de ossos e carne & 66 & 141 & 1,1 & 206 & 5,0 & 3,5 & 2,6 & 7,3 & 2,2 & 2,0 & 69 & 2,2 & 374 & 9,5 \\
\hline Cobertura morta & 9,9 & 1,7 & 6,3 & 6,0 & 2,7 & 1,2 & 2,6 & 0,3 & 1,1 & 3,9 & 59 & 4,0 & 479 & 50 \\
\hline
\end{tabular}




\section{RESULTADO E DISCUSSÃO}

Com a aplicação dos adubos orgânicos, observouse aumento significativo do $\mathrm{pH}$ do solo em todos os tratamentos e em todas as profundidades, efeito este positivo para a cultura, uma vez que tal aumento promove maior disponibilidade de nutrientes. Tal fato não foi observado apenas para o tratamento com farinha de ossos e carne na primeira profundidade, que não diferiu do tratamento mineral (Quadro 3). Observa-se o $\mathrm{pH}$ do solo adubado com fertilizante mineral mais ácido que o adubado com adubos orgânicos. A elevação significativa do $\mathrm{pH}$ do solo adubado com compostos orgânicos pode ser atribuída ao fato da formação de radical amina, $\mathrm{R}-\mathrm{NH}_{2}$, processo conhecido com aminação (Tisdale \& Nelson, 1967). A acumulação de ânions orgânicos eleva o consumo de prótons em resposta à absorção de amônio, ou prótons produzidos durante o processo de nitrificação (Theodoro et al., 2003).

Atribui-se à uréia, que compõe o formulado 20-5-20 aplicado no maracujazeiro, o principal motivo para a redução do $\mathrm{pH}$, principalmente nas camadas mais profundas do solo. Adubos amídicos como a uréia e amoniacais têm a propriedade acidificante do solo, pois no processo de nitrificação há liberação de íons $\mathrm{H}^{+}$ (Tisdale \& Nelson, 1967; Marschner, 1995; Taiz \& Zaiger, 2004). Além disso, a própria absorção do amônio pelas plantas promove a redução do $\mathrm{pH}$ do solo devido à extrusão de prótons da raiz para a rizosfera (Marschner, 1995).

A condutividade elétrica apresentou-se mais elevada no tratamento com adubo mineral em todas as profundidades, quando comparado com todos os adubos orgânicos (Quadro 3). Na camada superior do solo, a maior diferença entre o tratamento mineral $\left(58,5 \mathrm{mS} \mathrm{m}^{-1}\right)$ foi observada com a adubação com raspa de mandioca $\left(20,6 \mathrm{mS} \mathrm{m}^{-1}\right)$. As diferenças observadas podem ser atribuídas tanto à alta solubilidade dos adubos que foram aplicados no tratamento mineral (uréia, $\mathrm{KCl}$ e superfosfato simples), que contribuiriam para a elevação da condutividade elétrica, quanto ao efeito dos compostos orgânicos aplicados na imobilização química e, ou, física dos sais solúveis (adsorção, complexação, quelação, etc.).

Os teores de $\mathrm{P}$ nos tratamentos adubados com torta de filtro, com e sem cobertura morta, e com farinha de ossos e carne, apresentaram-se superiores ao tratamento com adubo mineral na camada superficial, não sendo observado tal fato em maiores profundidades (Quadro 3). As diferenças observadas são muito altas - $321 \%$ a mais de P no solo adubado com farinha de ossos e carne e em média $179 \%$ a mais de $\mathrm{P}$ no solo adubado com torta de filtro. Esta superioridade explica-se pelo fato de a torta de filtro e principalmente a farinha de ossos e carne apresentarem em suas composições teores elevados desse nutriente (Quadro 2), o que era esperado. Além disso, possivelmente grande parte do $\mathrm{P}$ adicionado nas 8 aplicações de adubos orgânicos permaneceu na forma orgânica ou na forma de fosfato de cálcio, ficando localizado na superfície do solo.

Os baixos teores de K são reconhecidamente uma das limitações ao uso de compostos orgânicos (Quadro 2). Observou-se menor teor de K no solo com adubação orgânica em comparação com a adubação mineral, em virtude da maior adição desse com o adubo mineral (fórmula 20-5-20). Apenas o tratamento com esterco bovino não diferiu daquele com adubo mineral na média das três profundidades. As amostras de

Quadro 3. Efeito da aplicação de diferentes fontes de nutrientes e da profundidade de amostragem do solo sobre o pH, condutividade elétrica, teor de fósforo, cálcio e magnésio

\begin{tabular}{|c|c|c|c|c|c|c|c|c|c|c|c|c|c|c|c|}
\hline \multirow{3}{*}{ Trat. } & \multicolumn{3}{|c|}{$\mathbf{p H}$} & \multicolumn{3}{|c|}{$\mathbf{C E}$} & \multicolumn{3}{|c|}{$\mathbf{P}$} & \multicolumn{3}{|c|}{$\mathrm{Ca}^{2+}$} & \multicolumn{3}{|c|}{$\mathbf{M g}^{2+}$} \\
\hline & \multirow[b]{2}{*}{$0-5$} & \multirow[b]{2}{*}{$5-10$} & \multirow[b]{2}{*}{$10-15$} & \multirow[b]{2}{*}{$0-5$} & \multirow[b]{2}{*}{$5-10$} & \multirow[b]{2}{*}{$10-15$} & \multicolumn{3}{|c|}{ Profundidade $(\mathrm{cm})$} & \multirow[b]{2}{*}{$0-5$} & \multirow[b]{2}{*}{$5-10$} & \multirow[b]{2}{*}{$10-15$} & \multirow[b]{2}{*}{$0-5$} & \multirow[b]{2}{*}{$5-10$} & \multirow[b]{2}{*}{$10-15$} \\
\hline & & & & & & & $0-5$ & $5-10$ & $10-15$ & & & & & & \\
\hline & & & & & $\mathrm{mS} \mathrm{m}^{-1}$ & & $-\mathrm{m}$ & $\mathrm{g} \mathrm{dm}^{-3}$ & & & & $\mathrm{mmol}_{\mathrm{c}} \mathrm{d}$ & $\mathrm{dm}^{-3}$ & & \\
\hline $\mathrm{AQ}$ & $5,34 \mathrm{~A}$ & $4,35 \mathrm{~B}$ & $4,09 \mathrm{~B}$ & $58,5 \mathrm{~A}$ & $35,7 \mathrm{~B}$ & $23,7 \mathrm{C}$ & $297 \mathrm{~A}$ & $127 \mathrm{~A}$ & $76 \mathrm{~A}$ & $9,11 \mathrm{~A}$ & $4,11 \mathrm{~A}$ & $3,53 \mathrm{~A}$ & $3,17 \mathrm{~A}$ & $0,89 \mathrm{~A}$ & $3,81 \mathrm{~A}$ \\
\hline $\mathrm{RM}$ & $6,69+\mathrm{A}$ & $5,79^{+} \mathrm{B}$ & $5,48^{+} \mathrm{B}$ & $20,6^{\circ} \mathrm{A}$ & $9,1^{\cdot B}$ & $7,1^{\circ} \mathrm{B}$ & $159 \mathrm{~A}$ & $87 \mathrm{~A}$ & $72 \mathrm{~A}$ & $30,0^{+} \mathrm{A}$ & $11,4 \mathrm{~A}$ & $17,4 \mathrm{~A}$ & $9,93^{+} \mathrm{A}$ & $4,77 \mathrm{~B}$ & $2,73 \mathrm{~B}$ \\
\hline $\mathrm{EB}$ & $6,34+\mathrm{A}$ & $5,58^{+} \mathrm{B}$ & $5,51^{+} \mathrm{B}$ & $22,0^{-} \mathrm{A}$ & $10,9^{-B}$ & $7,7^{-B}$ & $225 \mathrm{~A}$ & $121 \mathrm{~A}$ & $71 \mathrm{~A}$ & $20,1 \mathrm{~A}$ & $14,3 \mathrm{~A}$ & $11,8 \mathrm{~A}$ & $19,7^{+} \mathrm{A}$ & $9,58+\mathrm{B}$ & $5,00 \mathrm{C}$ \\
\hline TF S/CM & $6,62+\mathrm{A}$ & $6,38^{+} \mathrm{A}$ & $5,52^{+} \mathrm{B}$ & $30,5 \cdot \mathrm{A}$ & $25,1^{-} \mathrm{A}$ & $12,4 \mathrm{~B}$ & $862^{+} \mathrm{A}$ & 204B & $89 \mathrm{~B}$ & $70,4^{+} \mathrm{A}$ & $44,0+\mathrm{B}$ & $18,8 \mathrm{C}$ & $7,97+\mathrm{A}$ & $4,51 \mathrm{AB}$ & $2,59 \mathrm{~B}$ \\
\hline FOC & $5,66 \mathrm{~A}$ & $4,96^{+} \mathrm{B}$ & $4,97^{+} \mathrm{B}$ & $27,8 \cdot \mathrm{A}$ & $9,7 \mathrm{~B}$ & $7,0^{\bullet} \mathrm{B}$ & $1250^{+} \mathrm{A}$ & $300 \mathrm{~B}$ & $175 \mathrm{~B}$ & $28,4^{+} \mathrm{A}$ & $14,9 \mathrm{~A}$ & $11,9 \mathrm{~A}$ & $4,67 \mathrm{~A}$ & $1,72 \mathrm{~A}$ & $1,49 \mathrm{~A}$ \\
\hline $\mathrm{TF} \mathrm{C} / \mathrm{CM}$ & $6,72^{+} \mathrm{A}$ & $6,18^{+} \mathrm{B}$ & $5,75^{+} \mathrm{C}$ & $36,8^{-} \mathrm{A}$ & $21,3^{-} \mathrm{B}$ & $13,3^{-B}$ & $797^{+} \mathrm{A}$ & 297B & $151 \mathrm{AB}$ & $85,3^{+} \mathrm{A}$ & $39,0+\mathrm{B}$ & $24,6+B$ & $11,5^{+} \mathrm{A}$ & $4,35 \mathrm{~B}$ & $3,28 \mathrm{~B}$ \\
\hline CV (\%) & & 3,7 & & & 27,2 & & & 81,7 & & & 42,2 & & & 46,2 & \\
\hline
\end{tabular}

Em cada linha, médias seguidas por + ou - são maiores ou menores que o tratamento testemunha (químico), respectivamente pelo teste de Dunnett a $5 \%$, não diferindo dos demais. Médias das profundidades seguidas de mesma letra na linha não diferem estatisticamente pelo teste de Tukey, a $5 \%$. AQ: adubo químico; TF: torta de filtro; EB: esterco bovino; RM: raspa de mandioca; FOC: farinha de osso e carne; CM: cobertura morta. 
solos das três camadas em média nos tratamentos adubados com materiais orgânicos apresentaram teores de K inferiores ao encontrado no adubo mineral (Quadro 6). A maior diferença foi observada no tratamento com farinha de ossos e carne, que apresentou cerca de $80 \%$ de redução nos teores desse nutriente no solo em comparação com o solo adubado com adubo mineral. Lana et al. (2003) relatam que, em solos arenosos com baixos teores de matéria orgânica e baixa capacidade de troca catiônica, cultivados em sistema de plantio convencional de manejo (aração e gradagem), o K é facilmente lixiviado. Mesmo este processo sendo mais intenso quando se utilizam fontes solúveis de $\mathrm{K}$, a alta freqüência de adubação mineral neste experimento foi suficiente para manter elevados os teores desse nutriente.

Observaram-se acréscimos consideráveis de $\mathrm{Ca}, \mathrm{Mg}$ e Na no solo adubado com os tratamentos orgânicos, principalmente na camada superior, diferindo significativamente do tratamento com adubo mineral (Quadros 3 e 4). Os menores teores de $\mathrm{Ca}, \mathrm{Mg}$ e $\mathrm{Na}$ no solo que recebeu adubação mineral podem ser atribuídos ao menor conteúdo desses nutrientes no fertilizante mineral aplicado, em comparação com o conteúdo encontrado nos adubos orgânicos (Quadro 2), além da pobreza natural do solo.

Observou-se que nas camadas superiores, exceto para o tratamento com farinha de ossos e carne, todos os adubos orgânicos promoveram um acréscimo no valor total da soma de bases do solo, em comparação com o tratamento mineral (Quadro 4). Os tratamentos adubados com torta de filtro foram os que promoveram maiores acréscimos nos valores da soma das bases. Enquanto o tratamento mineral apresentou $22 \mathrm{mmol}_{\mathrm{c}} \mathrm{dm}^{-3}$, sendo classificado como médio, segundo a CFSEMG (1999), a torta de filtro apresentou
$81,6 \mathrm{mmol}_{\mathrm{c}} \mathrm{dm}^{-3}$ sem cobertura morta e $102,3 \mathrm{mmol}_{\mathrm{c}} \mathrm{dm}^{-3}$ com cobertura morta, valores classificados como muito altos, segundo a CFSEMG (1999). A torta de filtro promoveu acréscimos desses valores também em maiores profundidades (50 e 45,4 $\mathrm{mmol}_{\mathrm{c}} \mathrm{dm}^{-3}$ ), fato esse desejável por promover a geração de mais pontos de troca catiônica no solo (Quadro 4).

Seguindo os resultados encontrados para a soma de bases, os resultados da CTC da camada superior do solo adubado com torta de filtro foram significativamente superiores aos do solo adubado quimicamente, sendo de $65 \%$ quando sem cobertura e de $95 \%$ quando com cobertura morta (Quadro 4). Vários fatores podem ter contribuído para o aumento significativo da CTC do solo adubado com torta de filtro, como o teor de matéria orgânica, a quantidade de argila nesse material, além do tipo e da superfície específica dessa argila. Quanto maior essa superfície, maior será a sua CTC por aumentar a área de contato, melhorando a adsorção catiônica (Dadalto \& Fulin, 2001). Tais resultados são importantes principalmente pelo fato de a região em estudo apresentar solos arenosos, que geralmente têm baixa CTC e apresentam-se mais susceptíveis à perda de nutrientes por lixiviação.

Quanto ao teor de Al no solo, observa-se que os tratamentos adubados com fertilizante mineral apresentaram valores muito superiores aos encontrados nos adubados com compostos orgânicos (Quadro 4). O tratamento com a redução de Al menos expressiva entre os orgânicos (farinha de ossos e carne) apresentou valores $75 \%$, 82 \% e $98 \%$ menores que os encontrados no tratamento mineral, respectivamente para as diferentes profundidades (Quadro 4). Outros tratamentos orgânicos, principalmente a torta de

Quadro 4. Efeito da aplicação de diferentes fontes de nutrientes e da profundidade de amostragem do solo sobre o teor de sódio, alumínio e dos valores da soma de bases e da CTC pH 7 dos solos

\begin{tabular}{|c|c|c|c|c|c|c|c|c|c|c|c|c|}
\hline \multirow{3}{*}{ Tratamento } & \multicolumn{3}{|c|}{$\mathrm{Na}^{+}$} & \multicolumn{3}{|c|}{$\mathrm{Al}^{3+}$} & \multicolumn{3}{|c|}{ SB } & \multicolumn{3}{|c|}{ CTC pH 7} \\
\hline & \multicolumn{12}{|c|}{ Profundidade $(\mathrm{cm})$} \\
\hline & $0-5$ & 5-10 & $10-15$ & $0-5$ & $5-10$ & $10-15$ & $0-5$ & $5-10$ & $10-15$ & 0-5 & $5-10$ & $10-15$ \\
\hline & \multicolumn{12}{|c|}{$\mathrm{mmol}_{\mathrm{c}} \mathrm{dm}^{-3}$} \\
\hline Adubo químico & $0,57 \mathrm{a}$ & $0,32 \mathrm{a}$ & $0,24 \mathrm{a}$ & $1,00 \mathrm{c}$ & $5,37 \mathrm{~b}$ & $8,00 \mathrm{a}$ & $22,0 \mathrm{a}$ & $10,5 \mathrm{a}$ & $11,0 \mathrm{a}$ & $59,3 \mathrm{a}$ & $53,6 \mathrm{a}$ & $52,7 \mathrm{a}$ \\
\hline Raspa de mandioca & $0,81 \mathrm{a}$ & $0,38 \mathrm{~b}$ & $0,30 \mathrm{~b}$ & $0,12 \mathrm{a}$ & $0,12-\mathrm{a}$ & $0,87 \cdot a$ & $46,5^{+} \mathrm{a}$ & $18,6 \mathrm{~b}$ & $21,8 b$ & $61,7 \mathrm{a}$ & $40,7 \mathrm{a}$ & $41,8 \mathrm{a}$ \\
\hline Esterco bovino & $0,48 \mathrm{a}$ & $0,29 b$ & $0,16 \mathrm{a}$ & $0,00 \mathrm{a}$ & $0,50 \cdot \mathrm{a}$ & $0,12 \cdot \mathrm{a}$ & $47,8^{+} \mathrm{a}$ & $27,0 \mathrm{Ab}$ & $18,9 b$ & $67,6 \mathrm{a}$ & $48,0 \mathrm{ab}$ & $40,9 \mathrm{~b}$ \\
\hline Torta de filtro sem CM & $0,97+a$ & $0,46 \mathrm{~b}$ & $0,13 \mathrm{~b}$ & $0,00 \mathrm{a}$ & $0,37-\mathrm{a}$ & $0,00-\mathrm{a}$ & $81,6^{+} \mathrm{a}$ & $50,0+\mathrm{b}$ & $21,9 \mathrm{c}$ & $98,3^{+} \mathrm{a}$ & $69,4 \mathrm{~b}$ & $50,8 \mathrm{~b}$ \\
\hline Farinha de ossos e carne & $2,83^{+} \mathrm{a}$ & $0,74^{+} \mathrm{b}$ & $0,51 b$ & $0,25 \mathrm{a}$ & $1,00-\mathrm{a}$ & $0,87 \cdot a$ & $38,4^{+} \mathrm{a}$ & $18,1 \mathrm{ab}$ & $14,4 \mathrm{~b}$ & $61,0 \mathrm{a}$ & $46,3 \mathrm{ab}$ & $39,3 \mathrm{~b}$ \\
\hline Torta de filtro com CM & $1,20^{+} \mathrm{a}$ & $0,30 \mathrm{~b}$ & $0,23 \mathrm{~b}$ & $0,00 \mathrm{a}$ & $0,00-a$ & $0,12 \cdot \mathrm{a}$ & $102,3^{+} \mathrm{a}$ & $45,4^{+} \mathrm{b}$ & $28,8 b$ & $115,7^{+} \mathrm{a}$ & $66,5 b$ & $53,1 b$ \\
\hline $\mathrm{CV}(\%)$ & \multicolumn{3}{|c|}{35,1} & \multicolumn{4}{|c|}{103,0} & \multicolumn{2}{|l|}{37,6} & \multicolumn{3}{|c|}{20,8} \\
\hline
\end{tabular}

Em cada linha, médias seguidas por + ou - são maiores ou menores que o tratamento testemunha (químico), respectivamente pelo teste de Dunnett a $5 \%$. Médias das profundidades seguidas de mesma letra na linha não diferem estatisticamente, pelo teste de Tukey, a 5 \%. AQ: adubo químico; TF: torta de filtro; EB: esterco bovino; RM: raspa de mandioca; FOC: farinha de osso e carne; CM: cobertura morta. 
filtro, reduziram ainda mais os teores de $\mathrm{Al}$, chegando, em alguns casos, a apresentar um valor de $0,00 \mathrm{mmol}_{\mathrm{c}} \mathrm{dm}^{-3}$ (Quadro 4). A acidez potencial $(\mathrm{H}+\mathrm{Al})$ também evidenciou valores maiores no tratamento adubado com fertilizante mineral em relação aos tratamentos que receberam adubos orgânicos. Novamente a farinha de ossos e carne apresentou a redução menos expressiva, da ordem de 38 \%, em relação ao tratamento mineral (Quadro 6). A diminuição dos valores de $\mathrm{H}+\mathrm{Al}$ nos tratamentos que receberam adubos orgânicos é conseqüência do aumento do $\mathrm{pH}$ do solo

A aplicação de torta de filtro influenciou significativamente a granulometria da camada superior do solo $(0-5 \mathrm{~cm})$ em relação ao solo adubado com fertilizante mineral, verificando-se maiores teores de silte e argila e, consequentemente, diminuição relativa nos teores de areia (Quadro 5). Isto pode ser explicado principalmente pela presença de argila nos campos de plantio da cana, que também fica retida nos filtros das usinas, além de compostos orgânicos em decomposição, influenciando as frações mais finas do solo. O teor de argila no tratamento adubado com torta de filtro com cobertura representou um acréscimo da ordem de $122 \%$ em relação à adubação mineral. No tratamento com torta de filtro sem cobertura, o teor de argila foi $91 \%$ superior ao da adubação mineral. O valor total de silte no solo adubado com torta de filtro e cobertura morta também se mostrou superior ao do tratamento mineral, com acréscimo de cerca de 69 \%, não tendo havido efeito quando este resíduo foi utilizado sem cobertura morta. Os aumentos nas frações granulométricas mais finas (argila e silte) têm como conseqüência direta a redução relativa da fração granulométrica mais grosseira (areia). Em relação ao valor de areia total observado no tratamento mineral, o tratamento com a torta de filtro e cobertura morta sofreu redução de $9 \%$, e o sem cobertura morta, de 5,5 \%. Essas reduções se concentraram na fração areia grossa, sendo de $13,4 \%$ para a torta aplicada com cobertura morta e $7,4 \%$ quando aplicada sem cobertura morta, não havendo diferenças na fração de areia fina.

A adição de partículas finas, particularmente de argila, a um solo arenoso, como a que foi promovida pela adubação com torta de filtro neste trabalho, é certamente um fator de melhoria da qualidade do solo, pois incrementa a superfície específica e os atributos químicos e físicos dela dependentes, como a capacidade de retenção de água e de cátions.

Juntamente com o acréscimo na quantidade de argila e redução na de areia dos solos adubados com torta de filtro, observaram-se também acréscimos no teor de matéria orgânica (Quadro 5). Como a análise granulométrica foi feita sem a eliminação da matéria orgânica, esta pode ser em parte responsável pelo aumento verificado nas frações granulométricas mais finas deste tratamento. Observou-se aumento de $52 \%$ na matéria orgânica do solo adubado e torta de filtro com cobertura morta, em comparação ao adubado com fertilizante mineral (Quadro 5). O tratamento adubado com raspa de mandioca apresentou-se como o mais eficiente em disponibilizar matéria orgânica para o solo, com acréscimo de $79 \%$ em comparação com a adubação mineral. Não se observaram diferenças nas camadas mais profundas do solo.

O tratamento com raspa de mandioca, por promover o maior acréscimo de matéria orgânica do solo, também promoveu diferenças na densidade do solo, quando comparado com o adubado com fertilizante mineral. A redução, observada apenas na camada de 0-5 do solo (Quadro 6), foi de 14,5\%. Já a densidade das partículas das adubações orgânicas não diferiu da adubação mineral em nenhuma das profundidades (Quadro 5).

Quadro 5. Efeito da aplicação de diferentes fontes de nutrientes na camada superior do solo (0-5 $\mathrm{cm})$ sobre os valores de areia grossa, areia fina, areia total, silte, argila, matéria orgânica, densidade do solo e densidade da partícula

\begin{tabular}{|c|c|c|c|c|c|c|c|c|}
\hline \multirow{2}{*}{ Fonte } & \multirow{2}{*}{$\begin{array}{c}\text { Areia } \\
\text { grossa }\end{array}$} & \multirow{2}{*}{$\begin{array}{c}\text { Areia } \\
\text { fina }\end{array}$} & \multirow{2}{*}{$\begin{array}{c}\text { Areia } \\
\text { total }\end{array}$} & \multirow{2}{*}{ Silte } & \multirow{2}{*}{ Argila } & \multirow{2}{*}{ MO } & \multicolumn{2}{|c|}{ Densidade } \\
\hline & & & & & & & Solo & Partícula \\
\hline & & & $\mathrm{g} \mathrm{kg}^{-1}$ & & - & $\%$ & $\ldots \mathrm{kg} \mathrm{d}$ & $\mathrm{m}^{-3}$ \\
\hline Adubo químico & 715 & 196 & 911 & 44 & 45 & 2,03 & 1,449 & 2,703 \\
\hline Raspa e mandioca & 735 & 161 & 896 & 45 & 59 & $3,63^{+}$ & $1,258^{-}$ & 2,713 \\
\hline Esterco bovino & 717 & 183 & 900 & 39 & 61 & 2,19 & 1,372 & 2,771 \\
\hline Torta e filtro em CM & $662^{-}$ & 199 & $861^{-}$ & 53 & $86^{+}$ & $2,88^{+}$ & 1,443 & 2,698 \\
\hline Farinha e ossos carne & 722 & 193 & 915 & 31 & 54 & 2,14 & 1,444 & 2,747 \\
\hline Torta e filtro com CM & $619^{-}$ & 207 & $826^{-}$ & $74^{+}$ & $100^{+}$ & $3,09^{+}$ & 1,451 & 2,700 \\
\hline CV (\%) & 2,89 & 8,75 & 1,64 & 33,2 & 18,2 & 19,6 & 4,69 & 1,56 \\
\hline
\end{tabular}

Em cada linha, médias seguidas por + ou - são maiores ou menores que o tratamento testemunha (químico), respectivamente, pelo teste de Dunnett, a $5 \%$, não diferindo dos demais; CM: cobertura morta. 
Não foram observadas diferenças com a aplicação de adubos orgânicos, em relação à adubação mineral, para os valores de macroporosidade, microporosidade, porosidade total, capacidade de campo, ponto de murcha e água disponível em nenhuma das profundidades estudadas (Quadro 6). É importante observar a grande quantidade de macroporos, que, em média, ocupam mais de $2 / 3$ da porosidade total, em detrimento da quantidade de microporos, com cerca de 1/3. Para Kiehl (1979), o solo ideal teria a proporção de $1 / 3$ macroporos e $2 / 3$ de microporos.
Quanto à influência das profundidades nas características avaliadas, observa-se que as quantidades de areia fina e água disponível no solo não sofreram alterações nas diferentes profundidades (Quadro 7). Já os teores de $\mathrm{H}+\mathrm{Al}$ e as quantidades de areia grossa, areia total, da densidade do solo e da partícula aumentaram com o aumento da profundidade avaliada (Quadro 7). De forma contrária, os teores de $\mathrm{K}$ e as quantidades de silte, argila, matéria orgânica, macroporos, microporos, porosidade total, a capacidade de campo e o ponto de murcha permanente

Quadro 6. Efeito da aplicação de diferentes fontes de nutrientes na média das três profundidades amostradas do solo sobre os teores de potássio, $\mathrm{H}+\mathrm{Al}$, e sobre os valores de macroporosidade, microporosidade, porosidade total, capacidade de campo, ponto de murcha e água disponível

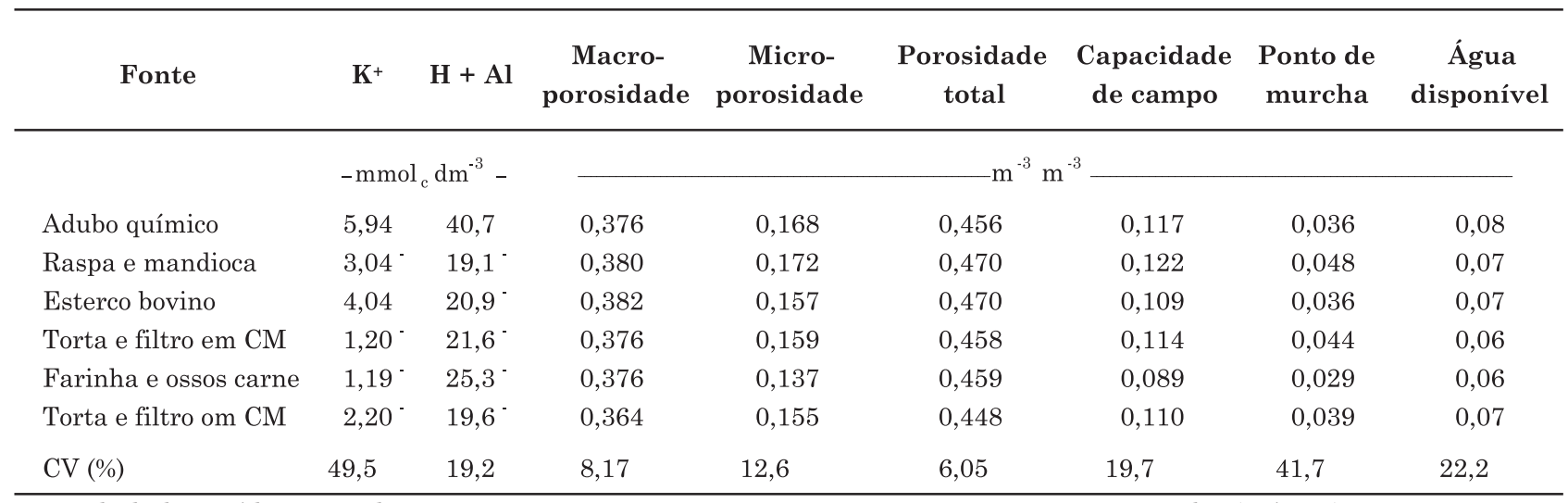

Em cada linha, médias seguidas por + ou - são maiores ou menores que o tratamento testemunha (químico), respectivamente, pelo teste de Dunnett, a $5 \%$, não diferindo os demais; CM: cobertura morta.

Quadro 7. Variação em profundidade na média de todos os tratamentos, dos teores de potássio, $\mathrm{H}+\mathrm{Al}$, e dos valores de areia grossa, areia fina, areia total, silte, argila, matéria orgânica, macroporosidade, microporosidade, porosidade total, densidade do solo, densidade da partícula, capacidade de campo, ponto de murcha e água disponível

\begin{tabular}{|c|c|c|c|}
\hline \multirow[b]{2}{*}{ Propriedade } & \multicolumn{3}{|c|}{ Profundidade $(\mathrm{cm})$} \\
\hline & $\mathbf{0}-\mathbf{5}$ & $5-10$ & $10-15$ \\
\hline Potássio $\left(\mathrm{mmol}_{\mathrm{c}} \mathrm{dm}^{-3}\right)$ & $5,20 \mathrm{~A}$ & $2,22 \mathrm{~B}$ & $1,38 \mathrm{~B}$ \\
\hline $\mathrm{H}+\mathrm{Al}\left(\mathrm{mmol}_{\mathrm{c}} \mathrm{dm}^{-3}\right)$ & $20,8 \mathrm{~B}$ & $25,8 \mathrm{~A}$ & $26,9 \mathrm{~A}$ \\
\hline Areia grossa $\left(\mathrm{g} \mathrm{kg}^{-1}\right)$ & $695 \mathrm{~B}$ & $720 \mathrm{~A}$ & $729 \mathrm{~A}$ \\
\hline Areia fina $\left(\mathrm{g} \mathrm{kg}^{-1}\right)$ & $189 \mathrm{~A}$ & $188 \mathrm{~A}$ & $185 \mathrm{~A}$ \\
\hline Areia total $\left(\mathrm{g} \mathrm{kg}^{-1}\right)$ & $885 \mathrm{~B}$ & $909 \mathrm{~A}$ & $915 \mathrm{~A}$ \\
\hline Silte $\left(\mathrm{g} \mathrm{kg}^{-1}\right)$ & $47 \mathrm{~A}$ & $34 \mathrm{~B}$ & $30 \mathrm{~B}$ \\
\hline Argila $\left(\mathrm{g} \mathrm{kg}^{-1}\right)$ & $66 \mathrm{~A}$ & $56 \mathrm{~B}$ & $54 \mathrm{~B}$ \\
\hline Matéria orgânica (dag dm-3) & $2,6 \mathrm{~A}$ & $1,8 \mathrm{~B}$ & $1,6 \mathrm{~B}$ \\
\hline Macroporos idade $\left(\mathrm{m}^{-3} \mathrm{~m}^{-3}\right)$ & $0,39 \mathrm{~A}$ & $0,37 \mathrm{~B}$ & $0,35 \mathrm{~B}$ \\
\hline Microporosidade $\left(\mathrm{m}^{-3} \mathrm{~m}^{-3}\right)$ & $0,17 \mathrm{~A}$ & $0,15 \mathrm{~B}$ & $0,15 B$ \\
\hline Porosidade total $\left(\mathrm{m}^{-3} \mathrm{~m}^{-3}\right)$ & $0,484 \mathrm{~A}$ & $0,457 \mathrm{~B}$ & $0,440 \mathrm{~B}$ \\
\hline Densidade solo $\left(\mathrm{kg} \mathrm{dm}^{-3}\right)$ & $1,40 \mathrm{~B}$ & $1,50 \mathrm{~A}$ & $1,54 \mathrm{~A}$ \\
\hline Densidade da partícula $\left(\mathrm{kg} \mathrm{dm}^{-3}\right)$ & $2,72 \mathrm{~B}$ & $2,76 \mathrm{~A}$ & $2,76 \mathrm{~A}$ \\
\hline Capacidade de campo $\left(\mathrm{m}^{-3} \mathrm{~m}^{-3}\right)$ & $0,12 \mathrm{~A}$ & $0,10 \mathrm{~B}$ & $0,10 \mathrm{~B}$ \\
\hline Ponto de murcha $\left(\mathrm{m}^{-3} \mathrm{~m}^{-3}\right)$ & $0,04 \mathrm{~A}$ & $0,03 \mathrm{~B}$ & $0,03 \mathrm{~B}$ \\
\hline Água disponível $\left(\mathrm{m}^{-3} \mathrm{~m}^{-3}\right)$ & $0,07 \mathrm{~A}$ & $0,07 \mathrm{~A}$ & $0,07 \mathrm{~A}$ \\
\hline
\end{tabular}

Médias seguidas de mesma letra na linha não diferem estatisticamente pelo teste de Tukey, a $5 \%$. 
diminuíram com o aumento das profundidades (Quadro 7).

\section{CONCLUSÕES}

1. Os adubos orgânicos aplicados no maracujazeiro promoveram aumentos do $\mathrm{pH}$ em todas as profundidades avaliadas e nos teores de diversos nutrientes no solo, principalmente na camada superior, além de promover redução significativa dos teores de $\mathrm{Al}$ nas camadas mais profundas.

2. Os tratamentos compostos por torta de filtro com e sem cobertura morta mostraram-se mais eficientes em promover melhorias nas características químicas do solo avaliado.

3. Apenas o tratamento adubado com esterco bovino mostrou-se eficiente em aumentar o potássio disponível no solo, em comparação com o adubo mineral.

4. Apenas os tratamentos com torta de filtro promoveram alterações na composição granulométrica do solo, reduzindo as quantidades de areia grossa e aumentando as quantidades de silte, argila e matéria orgânica nas camadas superficiais.

5. A raspa de mandioca foi o composto orgânico que promoveu maior aumento no teor de matéria orgânica do solo, além de reduções significativas na densidade do solo, em comparação com a adubação mineral tradicional.

\section{LITERATURA CITADA}

ABREU JUNIOR, C.H.; MURAOKA, T.; LAVORANTE, A.F. \& ALVAREZ, V.F.C. Condutividade elétrica, reação do solo e acidez potencial em solos adubados com composto de lixo. R. Bras. Ci. Solo, 24:645-657, 2000.

ANDERSON, J.M. \& INGRAM, J.S.I. Tropical soil biology and fertility. 2.ed. Wallingford, CAB Internacional, 1993. 221p.

CAVALLARO, N.; PADILLA, N. \& VILLARRUBIA, J. Sewage sludge effects on chemical properties of acid soils. Soil Sci., 156:63-70, 1993.

COMISSÃO DE FERTILIDADE DO SOLO DO ESTADO DE MINAS GERAIS - CFSMG. Recomendação para o uso de corretivos e fertilizantes em Minas Gerais. $5^{\text {a }}$ aproximação. Viçosa, MG, 1999. 359p.

DADALTO, G.G. \& FULLIN, E.A. Manual de recomendação de calagem e adubação pra o estado do Espírito Santo. $4^{\mathrm{a}}$ aproximação. Vitória, SEEA/INCAPER, 2001. 266p.

EMPRESA BRASILEIRA DE PESQUISA AGROPECUÁRIA EMBRAPA. Centro Nacional de Pesquisa de Solos. Manual e métodos de análise de solos. 2.ed. Rio de Janeiro, 1997. $212 \mathrm{p}$
GOMES, J.A.; SCAPIM, C.A.; BRACCINI, A.L.; FILHO, P.S.V.; SAGRILO, E. \& MORA, F. Adubações orgânica e mineral, produtividade do milho e características físicas e químicas de um Argissolo Vermelho- Amarelo. Acta Sci. Agron., 27:3:521-529, 2005.

HOLANDA, J.S.; TORRES FILHO, J. \& BEZERRA NETO, F. Alterações na fertilidade de dois solos adubados com esterco de curral e cultivados com caupi. R. Bras. Ci. Solo, 8:301-304, 1984.

KIEHL, E.J. Manual de edafologia: relações solo-planta. São Paulo, Ceres, 1979. 262p.

LANA, R.M.Q.; VILELA FILHO, C.E.; ZANÂO JUNIOR, L.A.; PEREIRA, H.S. \& LANA, A.M.Q. Adubação superficial com fósforo e potássio para soja. Scientia Agrária, Piracicaba, v. 4, n. 1/2, p. 53-60, 2003.

LIBARDI, P.L. Dinâmica da água no solo. Piracicaba, 1995. $497 \mathrm{p}$.

MARCIANO, C.R.; MORAES, S.O.; OLIVEIRA, F.C. \& MATTIAZZO, M.E. Efeito do lodo de esgoto e do composto de lixo urbano sobre a condutividade hidráulica de um Latossolo Amarelo saturado e não saturado. R. Bras. Ci. Solo, 25:1-9, 2001.

MARSCHNER, H. Mineral nutrition of higher plants. 2.ed. London, Academic Press, 1995. 889p.

MELO, W.J. \& MARQUES, M.O. Potencial do lodo de esgoto como fonte de nutrientes para as plantas. In: BETTIOL, W. \& CAMARGO, O.A., eds. Impacto ambiental do uso agrícola do lodo de esgoto. Jaguariúna, Embrapa Meio Ambiente, 2000. p.109-141.

OLIVEIRA, F.C.; MATIAZZO, M.E.; MARCIANO, C.R. \& ROSSETO, R. Efeitos de aplicações sucessivas de lodo de esgoto em Latossolo Amarelo Distrófico cultivado com cana-de- açucar: carbono orgânico, condutividade elétrica, pH e CTC. R. Bras. Ci. Solo, 26:505-519, 2002b.

OLIVEIRA, F.C.; MATTIAZZO, M.E.; MARCIANO, C.R. \& ABREU JUNIOR, C.H. Alterações em atributos químicos de um Latossolo pela aplicação de composto de lixo urbano. Pesq. Agropec. Bras., 37:529-538, 2002a.

SCHERER, E.E.; BALDISSERA, I.T. \& NESI, C.N. Propriedades químicas de um latossolo vermelho sob plantio direto e adubação com esterco de suínos. R. Bras. Ci. Solo, 31:123-131, 2007.

SILVA, J.E.; RESCK, D.V.S. \& SHARMA, R.D. Alternativa agronômica para o biossólido produzido no Distrito Federal. I - Efeito na produção de milho e adição de metais pesados em Latossolo no cerrado. R. Bras. Ci. Solo, 26:487-495, 2002.

TAIZ, L. \& ZEIGER, L. Fisiologia vegetal. 3.ed. Porto Alegre, Artmed, 2004. 719p.

THEODORO, V.C.A.; ALVARENGA, M.I.N. \& GUIMARAES, R.J. Alterações químicas em solo submetido a diferentes formas de manejo do cafeeiro. R. Bras. Ci. Solo, 27:10391047, 2003.

TISDALE, S.L. \& NELSON, W.L. Soil fertility and fertilizers. 2.ed. New York, Macmillan, 1966. 694p. 